\title{
Zarządzanie emisją z olejów opałowych zawierających frakcję oleju popirolitycznego
}

\begin{abstract}
Artykuł przedstawia możliwości wykorzystania frakcji popirolitycznej jako samoistnego paliwa lub jako komponentu olejów opałowych na podstawie uzyskanych wyników z badań i pomiarów emisji składników gazowo-pyłowych do atmosfery. Zarządzanie powstającymi emisjami pozwoli uzyskać informację na temat przebiegu procesu spalania skomponowanych paliw (zawierających frakcję popirolityczną) oraz porównać wielkości emitowanych zanieczyszczeń tego typu paliwa z tradycyjnymi olejami opałowymi.
\end{abstract}

Słowa kluczowe: emisja zanieczyszczeń do atmosfery, olej popirolityczny, piroliza zużytych opon.

\section{Managing emissions from heating fuels containing a fraction of post-pyrolithic oil}

The article presents the possibility of using a post-pyrolithic fraction as a spontaneous fuel, or as a component of heating fuels, based on the obtained measurements of emission of gaseous and particulate components into the atmosphere. Management of the resulting emissions will allow to obtain information on the combustion process of the composed fuels (containing postpyrolithic fraction) as well as the comparison of the amount of pollutants by this type of fuel with conventional heating oils.

Key words: emission of pollutants into the atmosphere, post-pyrolithic oil, pyrolysis of used tires.

\section{Wprowadzenie}

Na przestrzeni ostatniej dekady procesy pirolizy i zgazowania biomasy stałej, odpadów i pozostałości poprodukcyjnych lub komunalnych zyskują na coraz większym znaczeniu jako procesy, w których, oprócz energii elektrycznej i cieplnej, zaczęto uzyskiwać na skalę przemysłową paliwa ciekłe oraz gazowe. Poszukiwania surowców do pirolizy są kierowane przede wszystkim w stronę źródeł o charakterze odnawialnym lub odpadowym, umożliwiających jednocześnie redukcję gazów cieplarnianych oraz - w pewnym stopniu - uniezależnienie się od importu surowców kopalnych. Do surowców spełniających powyższe kryteria zaliczane są: biomasa (głównie o charakterze odpadowym) oraz oleje roślinne i thuszcze zwierzęce. Innymi rozpatrywanymi kierunkami są np. odzyskiwanie węglowodorów z odpadowych tworzyw sztucznych czy zużytych opon samochodowych poprzez ich segregację i dalszą przeróbkę [9].

Rozważając efekt ekonomiczny, należy stwierdzić, że wykorzystanie biomasy bądź odpadów tylko do produkcji ciepła w procesach bezpośredniego spalania lub współspalania jest ekonomicznie najmniej opłacalnym sposobem konwer-

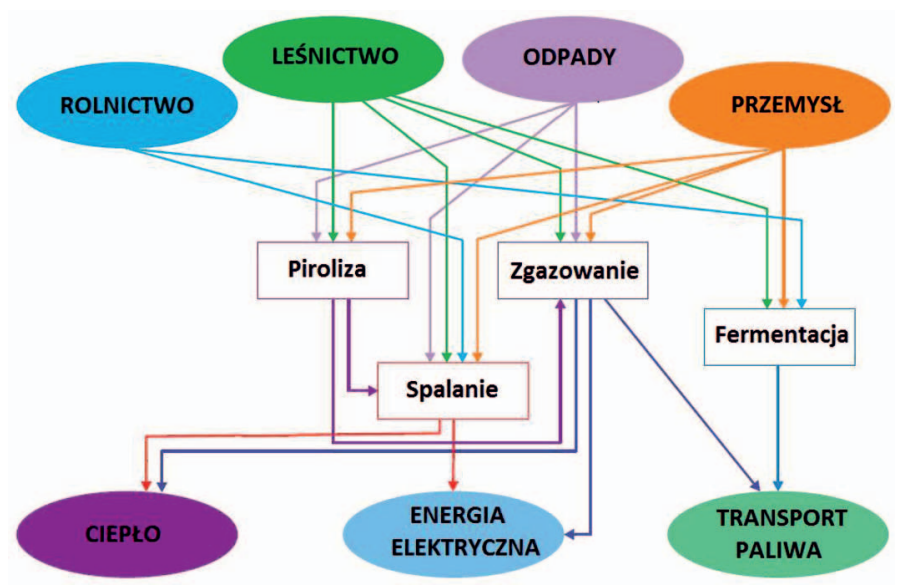

Rys. 1. Możliwości energetycznego wykorzystania surowców [13]

sji energii chemicznej w użyteczną. Efektywniejszym sposobem jest konwersja w układach kogeneracyjnych i trigeneracyjnych, ze względu na ich większą sprawność. Jednak najbardziej korzystna jest konwersja w biopaliwa ciekłe lub gazowe [8], ze względu na możliwość uzyskania użytecznych 
substancji chemicznych, paliw przy kogeneracyjnej produkcji energii elektrycznej i cieplnej [1,7].

Na rysunku 1 przedstawiono możliwości energetycznego wykorzystania różnego rodzaju surowców.

Piroliza to proces transformacji termicznej bogatych w węgiel substancji organicznych, który odbywa się w podwyższonych temperaturach, w środowisku całkowicie pozbawionym tlenu lub przy jego pomijalnie małej obecności. Proces ten jest z natury endotermiczny (wymaga dostarczenia ciepła z zewnątrz) i przebiega $w$ temperaturze do $1000^{\circ} \mathrm{C}$. Podczas procesu pirolizy masa odpadów zostaje przekształcona w gaz pirolityczny, koks pirolityczny i fazę ciekłą [2, 6]. Oprócz przedstawionych powyżej opisów, piroliza może być również alternatywą lub uzupełnieniem procesu spalania.

W zależności od szybkości nagrzewania wsadu, temperatury pracy reaktora oraz czasu przebywania w nim substratów, możliwe jest ukierunkowanie procesu na otrzymywanie jednego z trzech preferowanych produktów: karbonizatu, oleju bądź gazu $[1,7]$. Kontrola tych parametrów jest ważna, jeśli chcemy otrzymać np. więcej frakcji olejowej. Odpowiedni dobór parametrów procesu i jego nadzór pozwala na otrzymanie zamierzonego efektu procesu pirolizy. Najważniejszymi czynnikami decydującymi o rodzaju i ilości otrzymanych produktów są: rodzaj użytego surowca (odpadu), rodzaj reaktora, sposób ogrzewania, temperatury panujące wewnątrz reaktora, tempo nagrzewania wsadu, ciśnienie, sposób przygotowania wsadu, rozmiar cząstek wsadu, czas przebywania paliwa w reaktorze, natężenie przepływającego czynnika oraz rodzaj katalizatora w przypadku pirolizy biomasy $[6,8,10]$. Stosowanie np. umiarkowanego reżimu temperaturowego $\left(300 \div 500^{\circ} \mathrm{C}\right)$ umożliwia produkcję głównie oleju pirolitycznego, podczas gdy w wysokich temperaturach $\left(500 \div 900^{\circ} \mathrm{C}\right)$ preferowane jest wytwarzanie gazu $[1,7]$. Jeżeli substancja organiczna ogrzewana jest do temperatury około $500^{\circ} \mathrm{C}$ z szybkością od kilku do kilkudziesięciu stopni na minutę, a lotne produkty procesu wydzielają się stopniowo, powodując, że składniki gazów reagują z innymi składnikami stałej pozostałości, czy oleju pirolitycznego, to taki proces nazywany jest pirolizą wolną. Powstałe pary są w sposób ciągły odprowadzane i formowane do oleju. Proces pirolizy wolnej może trwać kilka minut lub nawet kilkanaście godzin.

Optymalnym procesem otrzymywania oleju popirolitycznego jest piroliza szybka. Najważniejszymi cechami przemawiającymi za wykorzystaniem szybkiej pirolizy do produkcji biooleju z biomasy lub z odpadów są: krótki czas reakcji, możliwość szybkiego chłodzenia par, dające duże wydajności produktów płynnych, możliwość starannego i precyzyjnego doboru warunków temperaturowych reakcji. Podstawowe parametry szybkiej pirolizy to: bardzo szybkie ogrzewanie (okoto $500 \div 1000^{\circ} \mathrm{C} / \mathrm{min}$ ), temperatura reakcji $425 \div 500^{\circ} \mathrm{C}$ (przy szybkim ogrzewaniu wzrasta wydajność części lotnych i za- chodzi mniej reakcji wtórnych) [11], krótki czas procesu, szybkie schładzanie lotnych produktów do oleju/biooleju. W wyniku szybkiej pirolizy substancja organiczna rozkłada się do par, aerozoli i stałej pozostałości. Pary i aerozole po ochłodzeniu i kondensacji tworzą ciemnobrązową ciecz. W zależności od rodzaju użytego wsadu, powstaje $60 \div 70 \%(\mathrm{~m} / \mathrm{m})$ ciekłego oleju, $15 \div 25 \%(\mathrm{~m} / \mathrm{m})$ stałej pozostałości i 10 $\div 20 \%(\mathrm{~m} / \mathrm{m})$ nieskroplonych gazów. Szybkie ogrzewanie i szybkie chłodzenie powoduje powstawanie wysokocząsteczkowych gazów podstawowego produktu - oleju/biooleju. W wyższej temperaturze głównym produktem jest gaz. Krótki czas reakcji minimalizuje tworzenie stałej pozostałości. Wytwarzany w szybkiej pirolizie olej stanowi produkt przeznaczony do dalszej przeróbki, a stała pozostałość i gazy są zawracane do procesu i wykorzystywane jako paliwo.

Oprócz przedstawionych czynników mających decydujące znaczenie na przebieg pirolizy, należy jeszcze wskazać czynnik, który wpływa na właściwości produktów otrzymanych z pirolizy. Tym czynnikiem jest rodzaj stosowanego surowca (odpadu, biomasy, paliwa). Ponieważ praca dotyczy oleju popirolitycznego uzyskanego z termicznej obróbki zużytych opon, stąd w dalszej części pracy skupimy się na odpadach, powstających z zużytych opon samochodowych. Wyeksploatowane opony samochodowe stają się coraz większym problemem. W $2000 \mathrm{r}$. w Polsce ich liczba sięgała blisko 115 tys. ton, a w 2005 r. było to już 131 tys. ton. Przewiduje się, że w roku 2022 szacowana masa zużytych opon osiągnie poziom 212,4 tys. ton. Zgodnie z prawem europejskim [15], od 1 lipca 2003 r. wprowadzono zakaz składowania na składowiskach zużytych opon, a od 1 lipca 2006 r. również elementów opon. Funkcjonujący w kraju system zagospodarowania zużytych opon samochodowych skupia się na odzysku energetycznym, recyklingu materiałowym i bieżnikowaniu. Piroliza jest więc dodatkowym atrakcyjnym uzupełnieniem stosowanych metod utylizacji opon.

Uzyskiwany z procesu pirolizy olej popirolityczny jest ciemną, mętną i gęstą cieczą o dość intensywnym zapachu. Składa się głównie z nasyconych i nienasyconych węglowodorów łańcuchowych i cyklicznych, a także aromatycznych o liczbie atomów węgla od 7 do 20. Mogą również pojawić się w nim substancje żywiczne. Wartość opałowa oleju pirolitycznego wynosi około $40 \mathrm{MJ} / \mathrm{kg}$, lepkość od $7 \mathrm{~mm}^{2} / \mathrm{s}$ do $36,2 \mathrm{~mm}^{2} / \mathrm{s}$, gęstość od $0,880 \mathrm{~g} / \mathrm{cm}^{3}$ do $1,100 \mathrm{~g} / \mathrm{cm}^{3}$ [5]. Ponieważ w procesie wulkanizacji gumy jednym $\mathrm{z}$ najistotniejszych składników jest siarka, to oleje pirolityczne uzyskiwane z opon charakteryzuje duża jej zawartość - nawet powyżej $1 \%(\mathrm{~m} / \mathrm{m})$. W związku z tym najczęściej nie mogą być bezpośrednio wykorzystane, np. jako paliwo silnikowe [3-5]. Olej popirolityczny wyjątkowo może być zamiennikiem oleju opałowego, pod warunkiem wyselekcjonowania tych partii towaru, które spełniają normy przewidziane dla oleju opałowego. 
Takim selekcjonowaniem zajmują się jedynie firmy dysponujące dużym zapleczem magazynowym i rafineryjnym, z możliwością blendowania paliw i z możliwością zagospodarowania na inne produkty tych partii towaru, które nie spełniają norm przewidzianych dla oleju opałowego [12]. Stosowanie paliwa o zmiennych parametrach - szczególnie lepkości, gęstości, wartości opałowej - powoduje zmianę warunków przebiegu procesu spalania. W kotłowniach niezautomatyzowanych wymaga to zmiany nastawienia palnika - pod groźbą pogorszenia składu spalin i idących za tym konsekwencji.
Ponadto na rynku znajdują się różne inne „oleje popirolityczne”. Kupując produkt pod tą nazwą, równie dobrze możemy kupić olej popirolityczny, pochodzący z pirolizy opon, który ma inny skład chemiczny od klasycznego oleju popirolitycznego z krakingu parowego i inaczej się pali, jak również olej popirolityczny z tworzyw sztucznych (całkowicie odmienny składem od pozostałych i mogący zawierać związki chloru) [12]. Stąd tak istotny dla producenta paliw staje się dobór wytwórcy oleju popirolitycznego, który zagwarantuje dostarczanie produktu o odpowiednich właściwościach.

\section{Część doświadczalna}

Koncepcja pracy przewidywała zrealizowanie jej następujących etapów:

- pozyskanie próbki oleju popirolitycznego do badań,

- rozdestylowanie szerokiej frakcji popirolitycznej na frakcje paliwowe i stałą pozostałość,

- wykonanie podstawowych badań fizykochemicznych dla otrzymanych paliw,

- przygotowanie frakcji olejowej z oleju popirolitycznego oraz mieszanek paliwowych do badań na badawczej instalacji kotłowej,

- przygotowanie stanowiska badawczego oraz aparatury pomiarowej,

- przeprowadzenie procesu spalania dla czterech próbek oleju napędowego grzewczego (podczas procesu spalania będą prowadzone pomiary zawartości $\mathrm{O}_{2}$ oraz stężeń zanieczyszczeń obecnych w gazach odlotowych, tj. $\mathrm{CO}_{2}, \mathrm{CO}$, $\mathrm{NO}, \mathrm{NO}_{2}, \mathrm{NO}_{\mathrm{x}}, \mathrm{SO}_{2}, \mathrm{CH}_{\mathrm{x}}$ ),

- pobór masy pyłu przy zastosowaniu filtracji wewnętrznej i wyznaczenie stężenia masy pyłu w warunkach zwężki pomiarowej,

- wykonanie obliczeń emisji na podstawie programów komputerowych.

W wyniku rozdestylowania szerokiej frakcji popirolitycznej uzyskano następujące produkty:

- frakcja do $149^{\circ} \mathrm{C}-810 \mathrm{ml}$, co stanowi $17,02 \%(V / V)$ wsadu (masa 646,6 g),

- frakcja $150 \div 371^{\circ} \mathrm{C}-2000 \mathrm{ml}$, co stanowi $48,11 \%(V / V)$ wsadu (masa 1828,3 g),

- stała pozostałość podestylacyjna - $1190 \mathrm{ml}$, co stanowi $34,87 \%$ ( $V / V)$ wsadu (masa $1230 \mathrm{~g}$ ).

W dalszych badaniach emisyjnych prowadzonych na stanowisku wyposażonym w kocioł olejowy Viessmann Paromat Triplex o mocy $80 \mathrm{~kW}$, wykorzystano frakcję olejową $150 \div 371^{\circ} \mathrm{C}$ oraz bazowy olej opałowy. Przygotowywano następujące paliwa badawcze:

- paliwo $1-100 \%(V / V)$ frakcja olejowa o zakresie wrzenia $150 \div 371^{\circ} \mathrm{C}$,
- paliwo $2-75 \%(V / V)$ frakcja $150 \div 371^{\circ} \mathrm{C}+25 \%(V / V)$ bazowego oleju opałowego,

- paliwo $3-50 \%(V / V)$ frakcja $150 \div 371{ }^{\circ} \mathrm{C}+50 \%(V / V)$ bazowego oleju opałowego,

- paliwo $4-100 \%(V / V)$ bazowego oleju opałowego.

Przy wykorzystaniu aparatury kontrolno-pomiarowej (automatyczny analizator spalin Madur GA-40Tplus firmy ELJACK oraz pyłomierz grawimetryczny P-10ZA wraz z wyposażeniem firmy ZAM Kęty) oraz informacji z norm: PN-Z 04030-7:1994 [17] uzyskano wyniki emisji, które przedstawiono w tablicy 1.

Na rysunkach 2 i 3 przedstawiono graficznie otrzymane wyniki badań emisji.

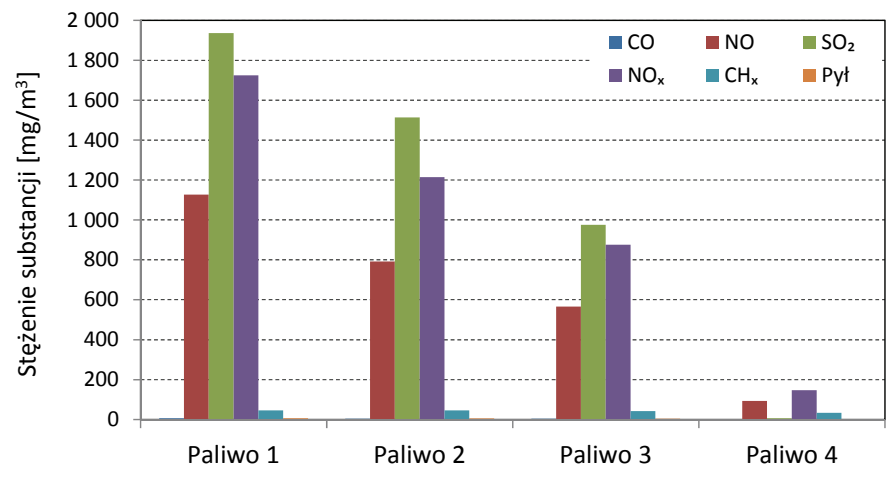

Rys. 2. Zestawienie wyników emisji zanieczyszczeń pyłowo-gazowych

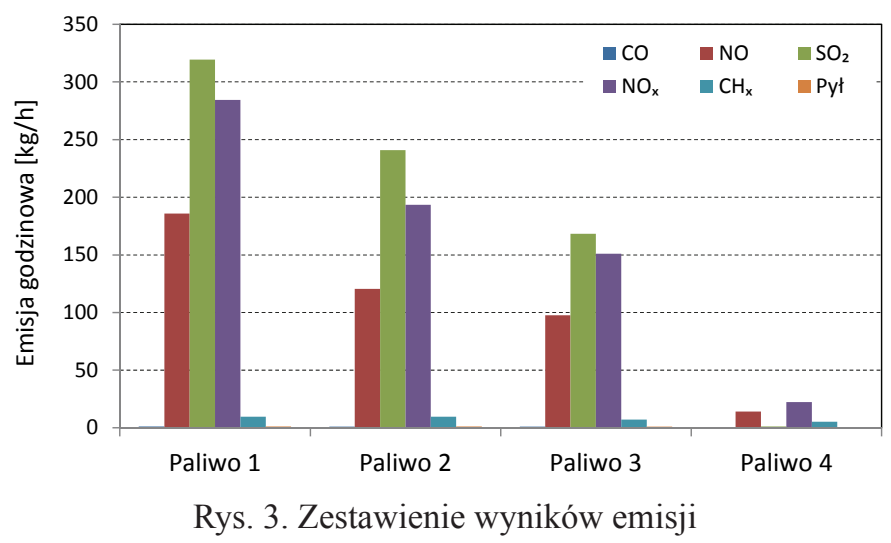

Rys. 3. Zestawienie wyników emisji 
Tablica 1. Zestawienie wyników pomiarów i obliczeń

\begin{tabular}{|c|c|c|c|c|c|c|}
\hline \multirow{2}{*}{\multicolumn{2}{|c|}{ Zakres badań }} & \multirow{3}{*}{$\begin{array}{c}\text { Jednostka } \\
\mathrm{hPa}\end{array}$} & \multicolumn{4}{|c|}{ Wyniki pomiarów } \\
\hline & & & \multirow{2}{*}{$\begin{array}{c}\text { paliwo } 1 \\
1005\end{array}$} & \multirow{2}{*}{$\begin{array}{c}\text { paliwo } 2 \\
1005\end{array}$} & \multirow{2}{*}{$\frac{\text { paliwo } 3}{1005}$} & \multirow{2}{*}{$\frac{\text { paliwo } 4}{1005}$} \\
\hline Worunli metoonlorisnn & ciśnienie atmosferyczne & & & & & \\
\hline 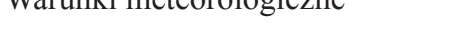 & temperatura otoczenia & $\mathrm{K}$ & 299 & 299 & 299 & 300 \\
\hline \multirow{9}{*}{ Parametry gazu w kanale } & średnica kanału & $\mathrm{m}$ & 0,18 & 0,18 & 0,18 & 0,18 \\
\hline & powierzchnia & $\mathrm{m}^{2}$ & 0,025 & 0,025 & 0,025 & 0,025 \\
\hline & temperatura gazu & $\mathrm{K}$ & 458 & 456 & 456 & 460 \\
\hline & ciśnienie statyczne & $\mathrm{hPa}$ & $-0,08$ & $-0,07$ & $-0,08$ & $-0,08$ \\
\hline & ciśnienie dynamiczne & $\mathrm{Pa}$ & 5 & 7 & 8 & 8 \\
\hline & stopień zwilżenia gazu $x$ & $\mathrm{~kg} / \mathrm{kg}$ & 0,033 & 0,030 & 0,029 & 0,025 \\
\hline & wilgotność & $\%$ & 4,10 & 3,73 & 3,61 & 3,11 \\
\hline & prędkość gazu & $\mathrm{m} / \mathrm{s}$ & 3,10 & 2,98 & 3,22 & 2,88 \\
\hline & $\begin{array}{l}\text { strumień objętości gazu } \\
\text { w warunkach pomiaru }\end{array}$ & $\mathrm{m}^{3} / \mathrm{h}$ & 279,0 & 268,2 & 290,0 & 258,8 \\
\hline $\begin{array}{l}\text { Parametry gazu w warunkach } \\
\text { umownych }\end{array}$ & $\begin{array}{c}\text { strumień objętości gazu } \\
\text { w warunkach pomiaru }\end{array}$ & $\mathrm{m}^{3} / \mathrm{h}$ & 164,9 & 159,2 & 172,3 & 152,3 \\
\hline \multirow{6}{*}{$\begin{array}{l}\text { Stężenie substancji w warunkach } \\
\text { umownych }\end{array}$} & $\mathrm{CO}$ & \multirow{6}{*}{$\mathrm{mg} / \mathrm{m}^{3}$} & 7 & 5 & 5 & 1 \\
\hline & NO & & 1127 & 792 & 567 & 93 \\
\hline & $\mathrm{SO}_{2}$ & & 1937 & 1513 & 976 & 7 \\
\hline & $\mathrm{NO}_{\mathrm{x}}$ & & 1725 & 1215 & 876 & 147 \\
\hline & $\mathrm{CH}_{\mathrm{x}}$ & & 46 & 46 & 42 & 34 \\
\hline & Pył & & 7 & 7 & 6 & 1 \\
\hline \multirow{6}{*}{ Emisja godzinowa } & $\mathrm{CO}$ & \multirow{6}{*}{$\mathrm{kg} / \mathrm{h}$} & 1,2 & 0,8 & 0,9 & 0,2 \\
\hline & $\mathrm{NO}$ & & 185,8 & 120,4 & 97,7 & 14,2 \\
\hline & $\mathrm{SO}_{2}$ & & 319,4 & 240,9 & 168,2 & 1,1 \\
\hline & $\mathrm{NO}_{\mathrm{x}}$ & & 284,5 & 193,4 & 150,9 & 22,4 \\
\hline & $\mathrm{CH}_{\mathrm{x}}$ & & 9,7 & 9,6 & 7,2 & 5,2 \\
\hline & Pył & & 1,2 & 1,1 & 1,0 & 0,2 \\
\hline
\end{tabular}

\section{Omówienie wyników badań}

Zastosowania oleju popirolitycznego jako zamiennika oleju opałowego według danych literaturowych (np. [12]) jest możliwe, pod warunkiem wyselekcjonowania frakcji, które spełniają normy przewidziane dla oleju opałowego. Stąd w pracy przeprowadzono proces rozdestylowania szerokiej frakcji popirolitycznej, który miał na celu uzyskanie frakcji paliwowych. W wyniku rozdestylowania uzyskano dwie frakcje paliwowe o zakresach wrzenia zbliżonych z benzynami silnikowymi oraz olejami opałowymi. Rozdestylowanie frakcji popirolitycznej w korzystny sposób wpłynęło na niektóre oznaczone parametry jakościowe wyselekcjonowanych produktów, tj. poprawiło: skład frakcyjny, lepkość kinematyczną oraz gęstość, ale nie spowodowało obniżenia zawartości siarki, zwłaszcza we frakcji olejowej. Właśnie ilość siarki oraz niska stabilność paliw popirolitycznych podczas przechowywania to główne czynniki, które ograniczają szersze zastosowa- nie wyselekcjonowanej frakcji olejowej z oleju popirolitycznego jako zamiennika dla olejów opałowych. Przechodząc do analizy wyników emisji otrzymanych podczas spalania próbek przygotowanych do badań, można stwierdzić, że paliwo 1, otrzymane z frakcji popirolitycznej, wyprodukowanej podczas pirolizy zużytych opon, wykazuje znacznie wyższe poziomy emisji składników gazowych w stosunku do typowego oleju opałowego. Podobną sytuację zaobserwowano również podczas spalania mieszanek oleju opałowego i frakcji olejowej popirolitycznej (paliwo 2 i 3). W obu przypadkach zanotowano wysokie stężenie $\mathrm{SO}_{2}$ oraz wysoką emisję tego składnika na poziomie od $168,2 \mathrm{~kg}$ do $319,4 \mathrm{~kg} \mathrm{SO} / \mathrm{h}$. W odniesieniu do tradycyjnego oleju opałowego, reprezentowanego przez paliwo 4 (poziom emisji 1,1 kg SO $2 / \mathrm{h}$ ), uzyskane wielkości emisji przez paliwa 1, 2 i 3 jednoznacznie pokazują, jak duża ilość $\mathrm{SO}_{2}$ jest emitowana do atmosfery. W przypadku 
tych samych próbek widoczny jest również znaczący wzrost emisji tlenków azotu, np. paliwo 1 zanotowało ponad 12-krotny wzrost ilości emitowanych tlenków azotu $\mathrm{NO}_{\mathrm{x}}$ aniżeli paliwo 4. Również pozostałe mierzone składniki spalin, tj. pył i niespalone węglowodory uzyskały wyższą emisję niż paliwo 4. Stąd konkluzja, że paliwo popirolityczne samo lub jako komponent w mieszankach z olejami opałowymi, znacząco podwyższa emisję toksycznych składników do atmosfery.

Podejmując się analizy spalania, należy również omówić przebieg procesu spalania oraz uzyskane parametry użytkowe przez instalację kotłową. Wszystkie przygotowane paliwa badawcze podczas spalania nie powodowały kłopotów eksploatacyjnych (np. przytykania filtrów i dyszy rozpylającej) ani nie wpływały negatywnie na pracę kotła olejowego. Ponadto uzyskano dla wszystkich próbek porównywalne parametry kotła, tzn. temperaturę $\left(183 \div 185^{\circ} \mathrm{C}\right)$ oraz sprawność energe- tyczną (około 92\%), co przełożyło się na podobne ilości energii cieplnej, wygenerowanej podczas spalania próbek badawczych $(1,65 \div 1,70 \mathrm{GJ})$.

Podsumowując otrzymane wyniki badań, można stwierdzić, że paliwa zawierające frakcję oleju popirolitycznego z zużytych opon samochodowych nie mogą być stosowane do eksploatacji na instalacjach kotłowych, które nie są wyposażone w systemy odsiarczania spalin i urządzenia odpylające. Odnosi się to głównie do małych i średniej mocy kotłowni olejowych, gdzie nie ma możliwości usunięcia nadmiarowej siarki oraz azotu z paliwa lub spalin. Oleje popirolityczne mogą być stosowane pod pewnymi warunkami jako paliwo na dużych przemysłowych instalacjach kotłowych, gdzie emisja składników toksycznych, takich jak: $\mathrm{SO}_{2}, \mathrm{NO}_{\mathrm{x}}$ czy pyłu nie jest istotna, gdyż te składniki są usuwane ze spalin przed wydostaniem się gazów do atmosfery.

Prosimy cytować jako: Nafta-Gaz 2018, nr 3, s. 252-256, DOI: 10.18668/NG.2018.03.10

Artykuł nadesłano do Redakcji 14.11.2017 r. Zatwierdzono do druku 2.02.2018 r.

Artykuł powstał na podstawie pracy statutowej pt.: Zarzadzanie emisja z paliw grzewczych zawierających frakcję oleju popirolitycznego - praca INiG - PIB na zlecenie MNiSW; nr zlecenia: 0098/TP/17/01, nr archiwalny: DK-4100-85/17.

\section{Literatura}

[1] Basau P.: Biomass Gasification and Pyrolysis. Practical design and Theory. Elsevier, Oxford 2010.

[2] Cherbański R., Wróblewski K., Molga E.: Badanie procesu pirolizy zużytych opon samochodowych $w$ reaktorze laboratoryjnym. Inżynieria i Aparatura Chemiczna 2016, nr 1, s. 016-017.

[3] Choi G-G., Jung S-H., Oh S-J., Kim J-S.: Total utilization of waste tire rubber through pyrolysis to obtain oils and $\mathrm{CO}_{2}$ activation of pyrolysis char. Fuel Processing Technology 2014, vol. 123, s. 57-64.

[4] Dębek C., Walendziewski J.: Hydrorefining of oil from pyrolysis of whole tyres for passenger cars and vans. Fuel 2015, vol. 159, s. 659-665.

[5] González J.F., Encinar J.M., Canito J.L., Rodríguez J.J.: Pyrolysis of automobile tyre waste. Influence of operating variables and kinetics study. Journal of Analytical and Applied Pyrolysis 2001, vol. 58-59, s. 667-683.

[6] Jaworski T.J.: Reaktory do pirolizy odpadów i biomasy. Piece Przemysłowe \& Kotty 2017, nr 1, s. 18-24.

[7] Klein M., Kluska J., Misiuk S., Kardaś D.: Przebieg i produkty procesu pirolizy wybranych tworzyw sztucznych $w$ reaktorze ciśnieniowym. Inżynieria i Aparatura Chemiczna 2011, vol. 50, nr 5, s. 54-55.

[8] Lewandowski W.M., Ryms M., Meler P.: Termiczno-chemiczna piroliza do biopaliw ciektych i gazowych, jako metoda podnoszenia sprawności konwersji energii biomasy. Nafta-Gaz 2010, nr 8, s. 674-680.

[9] Lubowicz J.: Weglowodory z odpadowych tworzyw sztucznych i biomasy. Nafta-Gaz 2009, nr 9, s. 712-717.

[10] Nadziakiewicz J., Wacławiak K., Stelmach S.: Procesy termicznej utylizacji odpadów. Wydawnictwo Politechniki Śląskiej, Gliwice 2012.

[11] Sinha S., Jhalani A., Ravi M.R., Ray A.: Modelling of Pyrolysis in Wood: A Review. SESI Journal 2000, vol. 10, nr 1, s. 41-62.
[12] Strona internetowa: http://warter.pl/pl-PL/olej_popirolityczny. html (dostęp: październik 2017).

[13] Wardach-Święcicka I., Cenian A., Polesek-Karczewska S., Kardaś D.: Wysokotemperaturowe zgazowanie biomasy odpadowej. Seminarium „Biomasa - Odpady - Energia 2011”, Gdańsk 10-11.03.2011.

\section{Akty prawne i normatywne}

[14] Dyrektywa Rady 1999/31/WE z dnia 26 kwietnia 1999 r. w sprawie składowania odpadów.

[15] Obwieszczenie marszałka sejmu Rzeczypospolitej Polskiej z dnia 4 września 2014 r. w sprawie ogłoszenia jednolitego tekstu ustawy o obowiązkach przedsiębiorców w zakresie gospodarowania niektórymi odpadami oraz o opłacie produktowej (Dz.U. z 2014 r., poz. 1413).

[16] PN-EN 13284-1:2007 Emisja ze źródet stacjonarnych - Oznaczanie masowego stężenia pyłu w zakresie niskich wartości - Część 1: Manualna metoda grawimetryczna.

[17] PN-Z 04030-7:1994 Badanie zawartości pylu-Pomiar stężenia i strumienia masy pytu w gazach odlotowych metoda grawimetryczna.

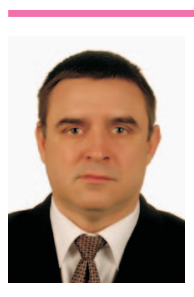

Mgr inż. Tomasz ŁACZEK

Starszy specjalista badawczo-techniczny w Zakładzie Paliw i Procesów Katalitycznych.

Instytut Nafty i Gazu - Państwowy Instytut Badawczy ul. Lubicz 25A

31-503 Kraków

E-mail: tomasz.laczek@inig.pl 